\title{
Pavlov's Methodological Behaviorism as a Pre-Socratic Contribution of the Melding of the Differential and Experimental Psychology
}

\author{
John J. Furedy \\ University of Toronto
}

\begin{abstract}
The differential/experimental distinction that Cronbach specified is important because any adequate account of psychological phenomena requires the recognition of the validity of both approaches, and a meaningful melding of the two. This paper suggests that Pavlov's work in psychology, based on earlier traditions of inquiry that can be traced back to the pre-Socratics, provides a potential way of achieving this melding, although such features as systematic rather than anecdotal methods of observation need to be added. Pavlov's methodological behaviorist approach is contrasted with metaphysical behaviorism (as exemplified explicitly in Watson and Skinner, and implicitly in the computer-metaphorical, informationprocessing explanations employed by current "cognitive" psychology). A common feature of the metaphysical approach is that individual-differences variables like sex are essentially ignored, or relegated to ideological categories such as the treatment of sex as merely a "social construction." Examples of research both before and after the "cognitive revolution" are presented where experimental and differential methods are melded, and individual differences are treated as phenomena worthy of investigation rather than as nuisance factors that merely add to experimental error.

Keywords: Pavlov, melding of experimental and differential psychology, methodological vs. metaphysical behaviorism, individual differences, sex differences, computer metaphor in current "cognitive" psychology
\end{abstract}

\begin{abstract}
La distinción diferencial/experimental que especificó Cronbach es importante porque una explicación adecuada del fenómeno psicológico requiere que reconozcamos la validez de los dos enfoques, a la par que una combinación de los mismos. Este trabajo trata de mostrar que la obra de Pavlov en psicología, basada en las primeras tradiciones investigadoras que se remontan hasta los presocráticos, proporciona una posible forma de conseguir esta combinación, aunque se deban añadir métodos de observación sistemática frente a la meramente anecdótica. Se contrasta el enfoque conductual metodológico de Pavlov con el conductismo metafísico, ejemplificado explícitamente en Watson y Skinner e implícitamente en las explicaciones del procesamiento de la información o de la metáfora computacional, empleadas por la psicología "cognitiva" actual. Una característica del enfoque metafísico es que variables diferenciales individuales como el sexo son básicamente ignoradas o relegadas a categorías ideológicas, como ocurre cuando se considera el sexo como mera "construcción social". Se presentan ejemplos de investigaciones, antes y después de la "revolución cognitiva", en los que los métodos experimental y diferencial se combinan, apareciendo las diferencias individuales como fenómenos dignos de investigación más que como factores molestos que meramente acrecientan el error experimental.

Palabras clave: Pavlov, unión complementaria de psicología diferencial y experimental, conductismo metodológico frente a metafísico, diferencias individuales, diferencias según el sexo, la metáfora computacional en la actual psicología "cognitiva"
\end{abstract}

I am indebted to Christine Furedy for clarification of earlier versions of this paper. I am also grateful to collaborating colleagues cited in this paper who carried out research in the Ege and Alberta laboratories on sex differences in animals and humans. They are not in full agreement with my interpretations of these results, but share the more general goal of melding differential and experimental psychological methods to investigate psychological functions.

Correspondence concerning this article should be addressed to John J. Furedy, Dept. of Psychology, 100 George Street, University of Toronto, Toronto, Ontario, M5S 3G3, Canada. E-mail: furedy@psych.utoronto.ca. 
Although psychology has many of the trappings of science, its intellectual status as a coherent discipline whose logical relations with the harder sciences are clear, is in increasing doubt. For example, in a symposium organized to discuss the status of psychology as a discipline (Furedy, 1990), the majority view among participants was that departments of psychology existed only as a matter of administrative convenience, in contrast to departments like that of physics, chemistry, and physiology.

Since then the situation has not improved. Many currently "hot" areas to which psychology is relevant (e.g., neuroscience) do not include the term itself. There is also an increasing tendency for academics who in the past classified themselves as social psychologists, experimental psychologists, developmental psychologists, comparative psychologists, and physiological psychologists to use classifications that exclude the term "psychology."

Psychology's "crisis of disunity" (Staats, 1983) is a disease with many diagnoses and proposed cures (e.g., Furedy, Church, Overmier, \& Spence, 1991). However, one of the most obvious symptoms is the lack of logical connections between various sub-areas, which all seems to have not only different foci of interest, but also a disagreement concerning how psychological phenomena should be approached. This gap has become a veritable chasm in the case of differential and experimental psychology. The former field, also known as individual differences, relies on correlational observational methods, while the latter seeks to manipulate independent variables.

The differential/experimental distinction was first conceptualized most clearly by Cronbach (1957) who argued, correctly in my view, that for any adequate account of psychological phenomena, the two approaches had to be melded. In this paper I shall suggest that Pavlov's work in psychology, based on earlier traditions of inquiry that can be traced back to the pre-Socratics, provides a potential way to achieve this melding. Partly because the other contributors to this series have focused on Pavlov's contributions to experimental psychology, I shall draw attention to his contribution to the field of individual differences as this approach has been combined with experimental psychological preparations. I begin with some elaborations of critical terms in my title. I then consider two differential/experimental melds that have Pavlovian roots, and that occurred before psychology's "cognitive revolution." This is followed by two examples of contemporary differential/experimental melds.

\section{Pavlov's Methodological Behaviorism and the "Greek Way of Thinking about the World"}

For western academic psychologists, behaviorism's origins lie in Watson's (1913) brand. The main impetus for this "revolution" was that controversies in experimental laboratories like those of Wundt and Titchener about whether thought could be imageless appeared to be untestable or quasi-theological, i.e., not resoluble through appeal to logic and evidence. Watson's behaviorism was metaphysical inasmuch as he advocated consigning "mentalistic" terms like thought, cognition, and feelings to the realm of the unreal, leaving behavior or observable responses to stimuli in the realm of real explanations. Psychology, in Watson's view, could only become a science if, in its explanations, it "emptied" the organism of all mental concepts. The most explicit modern version of this form of metaphysical behaviorism was Skinner's approach (often called "radical" behaviorism), in which cognition was denied any explanatory status; all psychological accounts of behavioral phenomena had to be formulated in terms of the (observable) connections between stimuli and responses. The main rationale underlying both the Watsonian and Skinnerian approaches is that they provide testable explanations. The validity of this rationale has been questioned (e.g., Furedy \& Riley, 1984). The problem is that it is doubtful, on closer examination, whether explanatory concepts like Watson's implicit-tonguemovements account of thought or Skinner's pastreinforcement-history account of individual differences provide genuinely falsifiable theories in terms of Popper's (1960) criterion of demarcation of what constitutes scientific theorizing.

A viable alternative to metaphysical behaviorism is the approach of methodological behaviorism. Metaphysical behaviorism of the sort advocated by Watson (1913) requires that not only the dependent variables, but also the explanatory constructs, be expressed in terms that require only "direct" observation. For Watson and his followers this meant that all behavioral or psychological phenomena that the living organism manifested had to be explained in terms of "observable" responses to physically specifiable stimuli. This implied the elimination of any inferred mental constructs, whether they be cognitive, affective, or conational.

In contrast, methodological behaviorism does not impose this sort of Watsonian restriction on psychological explanatory constructs. As long as the "evidence concerning those constructs [is] stated in an objective or scientifically communicable way" (Furedy, Heslegrave, \& Scher, 1984, p. 182), so that assumptions concerning the constructs are testable, the constructs themselves do not need to be "directly" observable, in a way analogous to constructs like gravity and electrons in physics.

Pavlov's approach to psychology can be described as a behaviorism that is methodological rather than metaphysical. Pavlov's own term "psychic," used to qualify reflexes, is one that is inimical to Watsonian or Skinnerian behaviorism. And while Pavlov's initial work was in physiology (for which he was awarded a Nobel Prize), he viewed his method, as applied to psychology, as entailing the objective study of mental processes (Furedy, 2003). In this he was probably influenced by the example of an older physiologist, 
Ivan Sechenov (1866), whose book as well as original title (before the censors forced him to change it) referred to "psychical processes" that were to be given a "physiological basis." Sechenov's formulation can be interpreted as a reductionist one, where causal links run only from physiological to psychological functions, but for Pavlov the "psychic" clearly existed as causal influences in their own right, and were not viewed either as functions that could be reduced to physiological ones, or as explanatory terms that needed to be eliminated, along Watsonian lines, for psychology to be scientific.

Rather, the "subjective psychology" that Pavlov opposed was an approach that proposed purposive or teleological explanatory "psychic" concepts, exemplified by such accounts as the assertion that "the saliva flowed because the dog wished to receive a choice bit of meat" (Grigorian, 1974, p. 433). Pavlov's opposition to this sort of teleological explanation rested on the lack of testability of the central assumption that underlay the explanation. In other, more current terms, Pavlov would not have denied that the feeling of intention existed as a genuine psychological phenomenon. His objection would have been to the use of intention as an explanatory construct, "basically because to state that $\mathrm{X}$ did $\mathrm{Y}$ because $\mathrm{X}$ wanted to do $\mathrm{Y}$ is circular as an explanation, and hence no explanation at all" (Furedy, 2003, p.10; see also Maze, 1983).

Methodological behaviorism, then, recognizes full teleological status for mental or psychological phenomena such as thoughts, feelings, and Pavlov's "psychic reflexes," but insists that explanations of these phenomena be specified in such a way that assertions about their fundamental characteristics are testable, or can be assessed by an appeal to logic and observable evidence. Essentially, this is the approach of an Australian brand of realism (Anderson, 1962) applied to psychology (Furedy, 1988). It also has older roots in the pre-Socratics, who were the first to advocate a disinterested approach to phenomena, and introduced what has been called the "Greek way of thinking about the world" (Burnet, 1930).

Disinterestedness is an investigative attitude that focuses on issues in a way that is independent of current interests and political powers. Of these interests, the most influential are those of a powerful state. It is a tribute to Pavlov's passion for his laboratory studies of the "psychic reflex" as well as his political acumen, that he was able to maintain an active laboratory in the twenties and thirties in the midst of the virtually all-powerful totalitarian regime run by Stalin. Pavlov's reputation, indeed, was so great that, as recalled by a young American scientist who was visiting Pavlov's laboratory at the time (Gantt, 1991, p. 68), he could even afford to be rude to the Minister of Education. This influential politician, in 1926, came to visit Pavlov's laboratory, but was refused hospitality on the grounds that Pavlov disagreed with his recent book, The $A B C$ of Communism.
Another principle of the pre-Socratics was that explanations had to "save the appearances." So, for example, when Thales, the earliest pre-Socratic, proposed that water was common to all things, he had to immediately contend the observation that things like trees and rocks were not, at least prima facie, made of (only) water. These observations or "appearances" had to be "saved" in the sense of being logically considered by the account put forward by the theorist. This epistemological or scientific sense of "saving" is quite different from the more ideological or political sense, where the (ideological) account is "protected" from the "appearances" by ignoring them, by placing them beyond the scientific pale (as metaphysical behaviorists have done with data based on self reports or introspection), or by supporting the account merely on the grounds that most current experts approve of them (a contemporary example from psychology, in my view, is the treatment of information-processing explanations applied to living organisms rather than just to computers).

Pavlov, I suggest, "saved the appearances" inasmuch as he was interested not only in observing the drops of saliva elicited by the bell conditional stimulus (CS) as a function of its being paired with the food unconditional stimulus (US), but also much more complex psychological phenomena such as neurosis. Specifically, the phenomenon he labeled "experimental neurosis" was produced by reducing the difference between the CS that was followed by food (CS+) and the CS that was not (CS-) to a point where the $(\mathrm{dog})$ subject could not discriminate. When subjected to this procedure, there was a behavioral breakdown such that the dogs could not perform easier discriminations that they had mastered previously. In other words, the emotional impact of failure to perform in a difficult discrimination task led to a breakdown in adaptive behavior, i.e., a form of neurosis, which, however was objectively assessed in terms of the drops of saliva induced by the $\mathrm{CS}+$ not being different in quantity from those induced by the CS-. It is also of interest that contemporary information-processing or contingency-analysing computermetaphorical models of conditioning that are based on the original Rescorla-Wagner (1972) model do not "save the appearance" of this sort of emotional, neurosis-producing consequence of failures to discriminate-computers have no such emotional hang-ups.

So far, the experimental neurosis concept provides an example of a motivational change induced by an experimental manipulation. However, perhaps partly because his canine subjects exhibited much more behavioral differences than the homogenously bred "little white test tube" (Osgood, 1953) albino rats so beloved by American learning theorists of the 30s, 40s, and 50s, Pavlov also stressed an individualdifferences aspect of experimental neurosis. Depending on the "strength of their nervous systems," he suggested that his dogs were more or less susceptible to developing neuroses, or changing their personalities, to the difficulty- 
in-discrimination challenge. The idea that living organisms differ in their capacity to produce neurotic behavior in the face of challenges is a concept not of experimental but differential psychology. The combination of the individualdifferences approach with the experimental one that Pavlov demonstrated can be contrasted with the typical current separation between the approaches of differential and experimental psychology. So only a handful of today's "cognitive" experimental psychologists (or "cognitive scientists") are concerned with individual differences as phenomena of interest in their own right. Rather, individual differences are viewed as a source of experimental error which must be "controlled" by running an adequately large number of subjects to obtain group "significance."

One advance that the science of psychology has made since Pavlov's days is the insistence on providing inferential statistics for the reliability of the observations that the researchers report. The requirement of statistical robustness was not met by Pavlov's laboratory, the methods of which were based on single-case studies, and a dependent-variable specification which did not meet the criteria for the assessment of the validity of statistical inference, and hence had only anecdotal rather than systematic evidential status. That this was more than of merely formal importance is suggested by the fact that although Pavlovian dog-salivary conditioning preparation was widely known to experimental psychologists since the early twenties, no body of systematic reports has been published in the journals of experimental psychology. This contrasts with the considerable body of conditioning literature based on the human eyelid preparation (especially in the fifties and sixties), and the even more reliable rabbit nictitating membrane preparation.

Still, while experimental psychologists are right to insist on the reliability of reported observations, many exhibit an unreasonable preference for "experimental" over "merely correlational" evidence. This prejudice is often manifested in the slogan that "A correlation does not imply a cause." The unexamined assumption that underlies this slogan is that a significant difference obtained in an experiment where an independent variable has been "manipulated" in an experimental tradition has clear causal implications, whereas a significant difference or correlation that has been merely observed in an individual-differences tradition has no such causal implications.

Like most prejudices, the one against correlations employed in differential psychology has a grain of truth. Even if $\mathrm{X}$ and $\mathrm{Y}$ are highly correlated, this does not prove that $\mathrm{X}$ causes $\mathrm{Y}$, or that $\mathrm{Y}$ causes $\mathrm{X}$. Indeed, both conclusions may be false in the case that some third factor, $\mathrm{Z}$, causes both $\mathrm{X}$ and Y. Similarly, when it is observed that X and $\mathrm{Y}$ are less highly, but still significantly, correlated, one cannot validly conclude whether $\mathrm{X}$ is a cause of $\mathrm{Y}, \mathrm{Y}$ is a cause of $\mathrm{X}$, or $\mathrm{Z}$ is a cause of both $\mathrm{X}$ and $\mathrm{Y}$.

However, this sort of proof of causality is also not available for observations reported in experimental psychology, when a variable $\mathrm{X}$ which the experimenter has manipulated produces a significant observed difference. The experimenter, of course, believes that $\mathrm{X}$ is a cause of the observed difference, but it is not only a logical possibility but usually a source of further argumentation that some other factor Y was also varied along with the (manipulated) $\mathrm{X}$ factor, and it is this confounding influence, $\mathrm{Y}$, that is the cause of the observed difference. Neither differential psychologists (who observe independent variables) nor experimental psychologists (who manipulate them) can produce results that "imply" or "prove" causality. All are engaged in attempts at (uncertain) inferences about causality, and it is the weight of evidence (which includes always imperfect attempts to eliminate confounding influences) that determines to what degree our hypotheses about causal factors are true. Accordingly, to return to Pavlov, although he did not employ the statistically quantitative measures of (manipulated) significant differences, or (observed) correlations, he was as interested in the experimental phenomenon of extinction (removal of the CS-US pairing) as he was in the differential strength-of-nervous system individual-differences phenomenon of resistance to experimental neurosis. It is this combination of experimental with differential psychology that is the aspect of Pavlov's methodological behaviorism that current scientific psychology, in my view, would be well advised to follow.

The cognitive revolution or "paradigm shift" (Segal \& Lachman, 1972) was preceded, especially in North American scientific psychology, by the dominance of the Hull-Spence S-R approach which focused on an experimental approach to learning theory, with little or no attention paid to individual differences. At first glance the behaviorism was of a methodological sort, in contrast to Watson and Skinner's explicit ruling out of mind and cognition on essentially metaphysical grounds. So Hullians engaged in experimentbased arguments with Tolman and his students concerning whether all learning was a function of S-R associations, or whether (as Tolman and his students argued), cognitive, S-S functions were also involved. Hull himself, at least in theory, was enthusiastic about the testability of a theory that was consciously modeled on Newton's, offering to buy a milk shake for anyone who provided an experimental refutation of his claims. And at least at the level of published work and informal comments, Spence was more interested in Tolman's views than in those of any other theorists who differed from the Hull-Spence S-R approach (see Kendler, 2002).

However, in practice, I suggest that Hull, Spence, and his students adopted a metaphysical brand of behaviorism, being unwilling to genuinely recognize the possibility that there really were cognitive, $\mathrm{S}-\mathrm{S}$ functions. To state this in pre-Socratic terms, they were not really concerned to "save the appearances" with respect to the observed phenomenon of cognition as a psychological function in living organisms.

The theoretical S-R construct that they employed as a substitute for cognition was the fractional anticipatory goal 
response (see, e.g., Spence, 1956). This was actually a Pavlovian concept, as the hypothetical response was said to be learned through classical conditioning. It was this construct that was invoked by S-R theorists from the 1930 s to the 1960 s to account, in S-R terms, for experimental results (mainly from "latent learning" studies that Tolman and his S-S learning followers put forward as evidence for cognitive, sign-significate, S-S learning).

In contrast to the clearly observable status of the CR with which Pavlov worked (i.e., drops of saliva elicited by the CS) or eye-blinks or nictitating membrane closures that were employed in Western laboratories, and were specifiable in terms of such aspects as frequency, magnitude, and amplitude, the observable or "behavioral" status of the Pavlovian or classically-conditioned fractional anticipatory goal response was much more dubious. In fact, one HullSpence proponent near the end of the construct's theoretical career described this purportedly observable response as "incorporeal," when he found that, contrary to Spence's (1956) explicit predictions based on stimulus-generalization principles applied to this hypothetical Pavlovian CR, the observed behavior of alley-running rats was not supportive (Moltz, 1957). The issuing of this spiritual qualifier for the fractional anticipatory goal response constituted a nice, albeit unintended, confirmation of MacCorquodale and Meehl's (1951) earlier charge that the contract was a deus ex machina mechanism used by S-R theorists to "smuggle" the concept of cognition into their purportedly thoroughgoing S-R accounts.

Another, more informal example that the behaviorism practiced by the dominant Hull-Spence S-R school was metaphysical (and hence inconsistent with Pavlov's approach) and not methodological, is the injunction that was issued to graduate students at the University of Iowa in the fifties and early sixties to ask not "What's on your mind?," but "What's on your behavior?" Of course this order, which sounds quite close to the Skinnerian approach to cognition, was not totally serious. Still, it was issued during Spence's chairmanship which was not, to say the least, totally laissez faire. For example, the design of all experiments run by faculty and graduate students at that time in the department were checked by Spence, and had to have his approval before the experiment could be run.

It may appear that the demise of the Hull-Spence S-R approach and the rise of the modern "cognitive" era in psychology liberated the discipline from the S-R approach's, metaphysical-behavioristic shackles. It is certainly true that one feature of the "cognitive paradigm shift" (Segal \& Lachman, 1972) was that in its formulations in such specific areas as Pavlovian conditioning, it was closer to Tolmanian S-S learning than to the Hullian S-R approach. So, for example, Pavlovian conditioning's currently most eminent exponent, following his influential early advocacy of the "contingency" approach to (all) Pavlovian conditioning (see., e.g., Rescorla, 1967), more recently, in an article written to a more generalist audience, "described" (my emphasis) Pavlovian conditioning as "the learning of relations among events" (Rescorla, 1988). This is essentially a cognitive, Tolmanian sign-significate position.

The liberation that a revolution promises, however, often turns out to be illusory. Certainly one can argue that there was less freedom during the days of The Terror that preceded Napoleon's rule than in the ancien regime that preceded the French Revolution. In the case of psychology's "cognitive" revolution, I suggest that it is at least arguable that all psychological functions have been banished into the realm of the (computer) metaphor, with the living organism being treated as if it were a computer. Not only cognitive, but also non-cognitive psychological functions are treated as if they were simply information-processing computer functions, with "input" and "output" replacing the Skinnerian stimuli and responses, respectively, and the conceptual organism being merely a "black box."

One sign that psychological explanatory concepts have been banished from the realm of reality is that in current "cognitive" psychology, the distinction itself between cognitive and non-cognitive psychological functions is one that most current psychological researchers cannot specify, in contrast to, say, experts in chemistry who can specify the distinction between acids and alkalis, or experts in physiology who can specify the distinction between the sympathetic and parasympathetic branches of the nervous system. Furthermore, consider some other basic psychological distinctions that have been observed since at least the time of Aristotle, distinctions like that between perception and conception (or cognition, in the pre-cognitiverevolutionary terminology), and learning and motivation (the latter being recognized, even in Hull's brand of behaviorism, in the terms, respectively, of habit strength and drive). None of these distinctions exist in computers which only process information (contrary to living organisms which do not-cf. Searle, 1992; Furedy, 1994), and they are recognized, if at all, only in a metaphorical sense as in the distinction between "hot" and "cold" cognitions.

So while modern experimental "cognitive" psychology is quite rigorous in specifying both the input (i.e., the conditions of the experiment) and output (i.e., some measurable aspect of behavior as reaction time or number correct in a memorized list of words), the behaviorism involved is metaphysical rather than methodological, as it has emptied the contents of the conceptual organism into a metaphorical bin. In that bin are fundamental issues (such as whether there is one or many systems of memory) which are not open to empirical investigation, being as untestable as the "past reinforcement history" that Skinnerians tried to use to account for different behavioral outcomes.

Yet another important feature of the various real psychological functions of living organisms, in contrast with the functions of computers, is the presence of individual differences. The North American experimental approach has, 
with some exceptions (of which one will be discussed below), regarded individual differences as a nuisance factor that reduces experimental or manipulational control. The Skinnerians have adopted the most radical solution to this perceived "problem" by working with and reporting experiments in which all subjects show the same phenomenon. So the peer-reviewed and quite high status Journal of the Experimental Analysis of Behavior reports only experimental phenomena where there is sufficient "stimulus control" that no inferential statistics are necessary.

Most other experimental approaches, both of the precognitive-revolutionary S-R days and of the current variety, recognize individual differences, but generally only as a problem to be "controlled" by the use of sufficiently large samples of subjects to provide convincing inferential statistics that testify to the statistical significance of differences purportedly produced by the experimental manipulations. In the next section I briefly discuss two examples of experimentalists in the fifties and sixties who combined experimental and differential approaches, and hence focused on individual-differences aspects of Pavlovian conditioning phenomena as topics of interest in their own right.

Two Examples of Pre-Cognitive-Revolution Differential/Experimental Combinations Rooted in the Pavlovian Approach

Probably the better known example of this sort of differential/experimental combination is the work of the late Eysenck at the Maudsley Institute of Psychiatry. Best known for his strong advocacy of the application of the objective, observational method to psychology, as well as his opposition to Freudian, psychoanalytic explanatory concepts (e.g., Eysenck, 1957). Eysenck developed questionnaires designed to measure such aspects of personality as the dimension of neuroticism. He explicitly related this concept to Pavlov's concept of strength of the nervous system and its relationship to the observed phenomenon of experimental neurosis, and provided data to suggest that Pavlovian (aversive) eyelid conditioning was related to an individual's position on the neuroticism scale, with neurotics conditioning better than normals.

At about the same time in American laboratories like that of the late Spence at the University of Iowa there were numerous experiments performed with the same aversive Pavlovian human eyelid conditioning preparation, and most (e.g., Spence, Haggard \& Ross, 1958) focused on experimental variables like US intensity, US duration, and the CS-US interval. This focus on experimental independent variables yielded considerable knowledge about Pavlovian conditioning that was of both theoretical and practical importance. For example, the fact that for any conditioning to occur at least in this particular preparation, the CS-US interval had to be very short, with optimal conditioning occurring with an interval between CS and US onsets of about $450 \mathrm{msec}$, and no conditioning at all when the CSUS interval was 2 seconds or greater. This was important especially for thoroughgoing S-R theories of conditioning (Jones, 1962; see also Furedy, 1989). In addition, it was of practical significance for applications of Pavlovian conditioning for teaching medically beneficial but hard-tolearn CRs like heart-rate deceleration with negative tilt as the US (Furedy \& Poulos, 1976; Furedy \& Klajner, 1978). In this preparation a 5-sec CS-US interval failed to yield any conditioning even when training sessions were repeated over several days (Furedy, 1992), whereas 1-sec CS-US intervals resulted in reliable heart-rate decelerative conditioning.

However, one of Spence's some $79 \mathrm{PhD}$ students, Taylor, who later married Spence and still later became an eminent social psychologist, was greatly interested in an individualdifferences "parameter" of human Pavlovian eyelid conditioning. Working along methodological behaviorist lines, Taylor constructed the Manifest Anxiety Scale (MAS) which was a questionnaire designed to assess individual differences in anxiety by employing a readily quantifiable index, i.e., number of anxiety-related items ticked off on the MAS questionnaire. This approach is contrary to a Freudian, more psychodynamic one that focuses on underlying mechanisms like that of repression, which are much more difficult to quantify, and are less "manifest." Still, the approach does recognize personality factors as real influences on behavior, even if, in Eysenck's approach, as there is an insistence on operational specifications (though not definitions) on how these factors are measured. And like Eysenck's neuroticism scale, the MAS was shown to be significantly correlated with eyelid conditioning in a number of studies, with subjects scoring high on the MAS yielding better conditioning.

The disagreement between the Maudsley and Iowa eyelid conditioning laboratories concerning whether the main independent individual-differences variable was neuroticism or (manifest) anxiety continued and was never resolved. But then neither were the disputes between such pre-Socratics as Thales and Heraclitus as to whether water or fire, respectively, was common to all things. The significance of the investigations initiated by Eysenck and Janet Taylor Spence lies not in the conclusions they drew, or even the validity of the specific instruments they respectively developed to assess neuroticism and anxiety. Rather this work is significant because it represents a combination of experimental and differential methods, and focuses needed attention on individual-differences phenomena as they affect phenomena associated with Pavlovian conditioning.

The currently dominant approach to Pavlovian conditioning (Rescorla, 1988) follows the basic assumptions of the famous Rescorla-Wagner (1972) model. In this approach there is little emphasis on the pre-Socratic principle of "saving the appearances," as the influence of the CS-US 
interval on Pavlovian conditioning is ignored: the mathematical Rescorla-Wagner model does not contain a parameter corresponding to the CS-US interval. Another "appearance" that is not "saved" in the model is the set of individual-differences variables that actually affect Pavlovian conditioning. Parameters of this sort do not appear in the model or in most current accounts of Pavlovian conditioning. Concepts like "associative strength," "associability," "surprisingness," CS/US contingency, and "salience" do all refer to independent variables that affect conditioning, but in none of these concepts are individual differences recognized, as was the case with Janet Spence's MAS or Eysenck's neuroticism scale.

The virtual ignoring of individual differences, or the use of poorly defined and unpromising differential independent variables, extends, indeed, to most of current experimental psychology. To take an example from modern experimental psychophysiology, the most commonly referred to differential concept has been the distinction between so-called "A" and "B" type personalities, with As being assumed to be more autonomically responsive than Bs. Even that rather elementary difference does not hold reliably in females for reasons that are far from clear (e.g., Macdougal, Dembroski, \& Krantz, 1981). More importantly, in contrast to the concepts like Pavlov's nervous system strength and Eysenck's neuroticism scale, the A/B distinction is not quantitative or dimensional, but is rather a qualitative typology that was developed by two physicians in the fifties rather than by psychologists specializing in personality theory. Moreover, experimenters seeking to employ the A/B distinction are faced with two unpalatable alternatives. One is to use the judgment of a trained clinician. This can produce a reliable classification which yields differential results (e.g., Scher, Hartman, Furedy \& Heslegrave, 1986), but the classification is obviously subjective and difficult to duplicate across laboratories and situations. The other alternative is to use the Jenkins scale for classifying A vs. B types. This procedure not only costs money and involves secret (and hence unscientific) methodology, but it is also rather ineffective in reliably producing differential results. It is not surprising that while this individual-differences concept continues to be popular in the media, experimental psychophysiological and psychological research with it has declined almost to zero in the last decade. And there has been little by way of developing new individual-differencesrelated variables for approaches that combine the experimental and differential psychological methods. The next section provides two recent examples of experimental preparations where the experimental and differential approaches have been combined.

\section{Two Recent Examples of Combining Experimental with Differential Psychological Methods: Sex Differences in Cognitive Functions}

The two examples presented in this section both involve sex as an independent variable that is associated with complex patterns of reliable differences in psychological functions. ${ }^{1}$

The conceptual shortcomings of the current computermetaphorical view of all psychological functions as involving "information processing" become especially apparent when one considers the "appearances" that are apparent even to casual, non-scientific observers. Even to these observers, it is obvious that there are differences in the way average men and women think. The commercial success of pop psychological explanations like the "Mars/Venus" distinction that is obvious even to observers uneducated in social or biological sciences indicates that, to put it technically, sex is an independent variable that is associated with differences in cognitive functioning that have a significant impact on behavior, including that aspect of behavior that is related to social interactions. Yet any information-processing computermetaphorical explanation cannot begin to provide an account for sex differences in cognitive functions, if only because sex is not a variable that occurs in computers. In addition, the oft-used hardware/software distinction, which is meant to parallel the heredity/environment or biological/societal distinction, is a poor analogy, if only because hardware and software are independent rather than interacting phenomena.

The second problem is that accounts referring to both biological and societal or psychological factors employ concepts on the psychological side that are much less precise than those on the physiological side. Whereas physiological distinctions (e.g., the difference between the sympathetic and the parasympathetic branches of the autonomic nervous system) are clear, psychological distinctions (e.g., those

\footnotetext{
1 I use the term "sex" rather than "gender" to describe this independent variable deliberately, and in opposition to the requirement of so-called "non-sexist" writing mandated by the very prestigious journals of the American Psychological Association. That requirement rests on assumptions of ideological feminism, that "sex is just a social construction"-that observed group sex differences are solely due to social and not at all to biological factors. This assumption is just as ideological and conceptually primitive as that of so-called "biological determinism", a position that ascribes sole causal status only to hereditary influences. Both these positions are contrary to the elementary tenet taught in almost all introductory psychology courses (although it seems to have been forgotten by many former introductory psychology students), that behavior is influenced not only by heredity and environment, but also the interaction of biological and societal factors.
} 
between "different memory systems") are not. Memory experts are divided as to whether memory is a single system comprising many "levels," or is a set of different systems. Nor is it clear what the conceptual distinction between "cognitive" and "non-cognitive" functions is. To add to the confusion, in many interdisciplinary bio-behavioral reports relating some physiological functions to "learning and memory," "cognitive" has become synonymous with "psychological."

This problem of taxonomic imprecision in psychological concepts stems from psychology's "cognitive revolution" of the 1970s that I have alluded to at the outset. In this "paradigm shift" (Segal and Lachman, 1972), the computer metaphor was taken into psychology, and the term "information processing" was then used to describe cognitive (and, indeed, all psychological) functioning.

Not all psychological research, however, is conceptually imprecise. In her extensive bio-behavioral examination of sex differences in Sex and Cognition, which brings together several decades of research work with both human and animal subjects, Kimura eschews the metaphorical, computereze terminology of "information processing," and employs fine taxonomical distinctions between different aspects of specific forms of cognitive abilities. For example, within the category of mathematical ability, she distinguishes between calculational performance (at which females tend to be better than males) and more abstract reasoning (at which males tend to do better), and relates these findings to equally precisely specified physiological factors such as differing brain areas and hormonal functioning (Kimura, 1999).

In work conducted since the mid nineties in the laboratories of Ege University's Center for Brain Research in Turkey on sex differences in animal and human cognitive functions directed by Professor Sakire Pogun, we have adopted an approach that also rejects information-processing concepts for psychological functions. ${ }^{2}$ Rather than dealing with fine-grained differentiations among cognitive abilities, however, we have focused on two broad psychological distinctions: that between cognitive ability and cognitive style, and between two levels of cognitive function - perceptual and conceptual. We also distinguish between cognitive and non-cognitive psychological functions in terms of whether or not they are propositional expressions to which the true/false category applies. Hence, emotions, motives, and stimulus-response associations are non-cognitive, as they cannot be categorized as true or false.

These distinctions are applicable to both human and nonhuman animals, and are also specifiable with the same level of operational precision that is used to make physiological distinctions. Their use allows recognition of various sorts of sexually-dimorphic behavioral phenomena to which physiological, brain-organizational mechanisms can be related. We suggest, moreover, that our approach not only yields testable hypotheses that can advance scientific understanding, but is relevant for applied problems (e.g., treating smoke addiction in a way that takes into account differences between the sexes). Essentially, this is the approach of methodological behaviorism adopted by Pavlov in which an individual-differences concept like strength of the nervous system could potentially be elucidated at least partly in terms of physiological (brain-related) mechanisms, as well as applied to human problems.

With sex rather than Pavlov-Eysenck strength of the nervous system as the individual-differences variable of interest, three aspects of this research are presented here. My aim is to illustrate how a methodological behaviorist approach (which includes reference to physiological factors in the explanations offered for the phenomena that have been observed) may lead to advances in scientific understanding, and to progress in biomedical applications. Common to the sexually-dimorphic phenomena examined is that they involve qualitative rather than quantitative differences: Sex of the subjects has a directionally different effect on how some other independent variable operates, rather than entailing merely a few points difference between males and females on some cognitive task. (This focus on qualitative sexual dimorphism is preferable in behavioral studies, where it is always possible that small quantitative group differences are due to errors of measurement, or some other confounding).

\section{Interactive Effects of Nicotine and Sex on the Traits of Cognitive Ability and Style in Humans}

The first aspect of this research includes reference to a serious contemporary health problem the gravity of which was not recognized in Pavlov's day: the markedly addictive habit of cigarette smoking. In the study (for details see Algan, Furedy, Demirgoren, Vincent \& Pogun, 1995) designed to obtain both scientifically relevant and potentially useful applied information, smoker and non-smoker female and male students were given a verbal task (whether two of three syllables presented make a meaningful word) and a spatial one (whether two of three figures presented are identical) in which reaction time, accuracy and the number of "no-responses" were recorded (Algan et al., 1995). The verbal (conceptual) task was harder than the spatial (perceptual) one. While reaction time and accuracy are the

\footnotetext{
2 Professor Pogun's opposition to information-processing concepts in psychology is not as strong as mine. For an account of her interpretation of these data, see Pogun (2001).
} 
main indices of cognitive ability, the number of no-responses reflects cognitive style. If a cautious approach is used in problem solving, the no-response rate would be higher; this measure is also negatively related to subjective confidence or "cognitive self esteem."

Among non-smokers, there were sex differences in ability: on the harder (and conceptual) verbal task, females were superior to males. This result is consistent with the findings in the literature for verbal cognitive tasks. However, male smokers performed better than non-smoker males and as well as non-smoker females. This is consistent with observations of the use of centrally acting nicotinic agents, such as are currently being investigated for their therapeutic potential in the treatment of Alzheimer's disease (e.g., Newhouse, Sunderland, Thompson, Tariot, Weingartner, Mueller et al., 1986; Sahakian, Jones, Levy, Gray \& Warburton, 1989).

Another interesting finding of this study relates to sex differences in cognitive strategy during problem solving, and the interaction with smoking status. Non-smoker females had a higher non-response rate than males but the nonresponse rate of smoker females decreased substantially in both tasks. This is a trait of cognitive style rather than of ability. The results suggest an increased level of cognitive self esteem in women smokers. This finding, if replicated, has implications for sex-differentiated smoke-cessation programs for the young.

\section{Sexually Dimorphic Cognitive Style in Rats in the Water Maze}

A variant of the water-maze (WM) preparation can be used to assess the effects of such variables as sex and nicotine on cognitive functioning in rats (Kanit et al., 1998). The WM is a circular body of water from which escape is provided by swimming to a platform. Decrease of escape latencies over trials reflects the cognitive learning of the proposition "Where the platform is." The water is opaque, so that having the platform above and below the water's surface produces both a visible and hidden condition. These visible and hidden conditions involve, respectively, perceptual and conceptual levels of cognitive functioning. The rats' perceptual and conceptual cognitive abilities can be assessed by presenting them with 12 days training ( 4 trials each, and each trial starting from different positions), where the platform is always in the same position, sometimes visible, sometimes hidden. A two-day "swim speed" test (rats had to swim between two platforms) before the experiments controlled for any group differences in non-cognitive abilities such as swim speed or motivation. We have consistently found no escape-latency differences as a function of sex and nicotine during the 12 interspersed perceptual and conceptual cognitive ability testing days. Group sex differences also failed to emerge during the first two "swim- speed" test days that evaluated non-cognitive group differences. Again, a Pavlovian connection is worth noting in this concern with the influence of non-cognitive, motivational factors on a preparation where the central focus is on (cognitive) associative learning. In the classical Pavlovian preparation, conditioning (i.e., CS-elicited salivation) was recognized to be influenced by the level of food deprivation in the dogs, and in later more systematically investigated classical conditioning preparations such as the eyelid one investigated by the Hull-Spence S-R school, the influence of motivational factors like drive was recognized and anchored in independent-variable manipulations such as the intensity of the (puff or shock) US.

While the swim-speed test is intended to depict noncognitive factors, and the 12 days of "learning the place of the platform" to measure cognitive ability, the third phase of the study is designed to illustrate cognitive style differences. The most sensitive test of these occurs on the first trial of the 13th day, when the platform is visible and shifted from its former distal position to be very proximal to the rat. The shift in position presents a conflict between old (now incorrect) conceptual knowledge and present (now correct) perceptual knowledge. Provided there have not been any group differences in non-cognitive factors and cognitive ability, any difference in escape latency on the shift trial can be attributed to differences in choice of cognitive style.

A dramatic sexually dimorphic effect has emerged in these WM studies in adult rats (Kanit et al., 2000a). Females have much lower escape latencies than males on this first proximal shift trial. Most females swim straight to the shifted visible platform that is "under their nose" and hence much closer than the previous platform location.

This proximal perceptual style effect is eliminated if nicotine is chronically given: then nicotinized females perform as poorly as males, and search around the quadrant where the platform used to be (Kanit et al., 1998). This sex difference is obviously not a cultural "social construct" but reflects differences in brain organization. But that is not to say that experiential factors may not be involved. One plausible interpretation is that the readiness for parenting plays a role, given that looking after pups appears to involve a more proximal perceptual style than other activities like foraging for food. This interpretation could be tested on two species of voles: meadow voles, the females of which are solely responsible for parenting, and prairie voles, whose males have a share in parenting. The prediction would be that the sex difference in the proximal perceptual style effect would emerge more markedly in meadow voles than in prairie voles, because the females in the former species have sole rather than just shared responsibility for parenting.

In animal studies it is possible to investigate biobehavioral links between the observed behavioral performance on the proximal shift trial and brain biochemical mechanisms involved in cognitive functioning. For example, we have studied the possible involvement of dopamine DA2 
receptors in the observed sexually dimorphic cognitive style effect in nicotine treated rats, and found no correlation between brain DA2 receptor activity and performance in the water maze (Kanit et al., 1998).

Again, nitric oxide (NO) has been previously implicated in "learning and memory processes." Recently, postexperimental NO assays (NO2 and NO3, stable metabolites of $\mathrm{NO}$, were determined) of cortical and hippocampal areas have indicated that cortical (but not hippocampal) NO and performance on the trial where the platform was proximal to the rat's starting position are positively correlated (Kanit et al., 2000b). In the choice between different cognitive styles, the cortex is involved, whereas the hippocampus has been clearly implicated in the literature as being involved in "place learning" or, in our terminology, conceptual cognitive learning ability.

The distinction between cognitive ability and style may have applied implications for human behavior, which may be more determined by style than by ability differences. The finding that many women with very high mathematical ability prefer careers in the life sciences rather than physical sciences (Kimura, 1999) could be interpreted in these terms. In teaching individuals to improve their performance in cognitive tasks, it may be more relevant to focus on appropriate cognitive styles for mastery (as in the case of the proximal shift trial in the rat WM preparation), rather than attempting to increase sheer cognitive ability. Finally, more focus on style rather than ability may also be relevant because many real-life cognitive tasks do not require individuals to use the limits of their cognitive ability, but rather to adopt the appropriate style of cognitive functioning.

\section{A Sexually-Dimorphic Reversed \\ Psychophysiological Effect of an Acute Smoking Manipulation on Transient Arousal}

The experiment described above (Algan et al., 1995) also included an acute nicotine manipulation. Smokers were deprived for a 10-hour period, and allowed to have one cigarette during a 15-minute rest period that separated two presentations of the cognitive tasks during which psychophysiological measures of cardiovascular function (heart rate) and electrodermal activity (skin resistance level) were recorded.

There was a marked increase of some 15 beats per minute to an equal extent between the sexes and between the conceptual verbal and perceptual spatial tasks (for details, see Furedy, Algan, Vincent, Demirgoren, Pogun, 1999). However, skin resistance level, which is an index of psychological arousal of the organism as a whole, showed a relative increase in the males, but a relative decrease in the females, although only during the (conceptual) verbal task and not during the (perceptual) spatial task. This objective measure of transient psychological arousal yielded a pattern of results that is opposite to the introspective-report or subjective measures reported in the literature, which indicate that females smoke for "relaxation" and males for "stimulation" (e.g., Spielberger, 1986).

Both the reliability of the phenomena and our interpretation of the experimental results are subject to further investigation through studies that check on robustness as well as studies that consider alternative hypotheses to those we advance. These further investigations should be facilitated by employing a psychological explanatory taxonomy that is not based on computer-metaphorical concepts, but rather has a level of precision comparable to that of physiological concepts. What seems already clear is that the combination of experimental and differential psychological methods (the latter is essentially the only one that can be used in human studies to observe the effects of independent variables like chronic, though not acute, smoking) yields possibilities for an advancement in scientific understanding that sole reliance on experimental methods does not provide.

The Orienting Reaction (OR) or Allocation-ofAttention Preparation as a Potential Marker for Male Schizophrenia

Pavlov was the first to identify what he termed as the surprise or orienting reaction (OR). He noted that the OR would disrupt the $\mathrm{CR}$ as when, for example, the presentation of the bell paired with the food failed to produce salivation when an external noise caused the dog to exhibit orienting such as pricking up its ears rather than the salivary CR. The OR concept was developed by Sokolov (1960, 1963), who asserted that ORs decreased or habituated to stimulus repetition, and increased or were "reinstated" to stimulus change. Sokolov's writings had a major impact on the theorizing of Western experimental psychophysiologists, especially on those concerned with the human Pavlovian autonomic preparation that employed tones or lights and shocks or loud noises as the CSs and USs respectively, and the electrodermal response (so-called "GSR") as the autonomic dependent variable. Although less robust and learning-like than the eyelid preparation (which produced orderly negatively-accelerating-towards-asymptote "learning" curves as a function of a large number of repeated CS-US trials), the human GSR preparation was theoretically attractive as a better "window" on the learning of the emotion of fear. It was, indeed, called human "fear conditioning."

As detailed elsewhere (Furedy \& Poulos, 1977), the Sokolovian OR concept posed a serious methodological problem for would-be GSR conditioners. This problem, which was first raised most trenchantly by Steward, Stern, Winokur, and Fredman (1961), and echoed later by influential researchers (e.g., Badia \& Defran, 1970; Prokasy \& Ebel, 1967), was the grave methodological confound that what was considered to be an autonomic CR was, in fact, merely a 
recovered or "reinstated" OR to change. This methodological criticism had special impact on the GSR "fear" conditioning preparation for at least two reasons. First, the GSR, in contrast to a response like salivation, occurs to neutral stimuli like the CS before it is paired with the US, so that the CS is not "neutral" before pairing with the US. Secondly, whereas ORs and CRs (or defensive responses in the case of aversive USs like shocks) can be differentiated either in terms of the observable nature of the response (ear-pricking in dogs elicited by change vs. salivation) or its onset latency (short versus longer in the case of tone-elicited blinks in the eyelid preparation which, moreover, decrease and increase, respectively, over reinforced trials), no such differentiation is evident in the case of the GSR.

The evaluation of this "merely an OR" versus "a true CR" argument concerning the human conditional GSR remains unresolved (see, e.g., Furedy \& Poulos, 1978 vs. Siddle \& Remington, 1978), and is a matter for specialists with a focus on the human Pavlovian GSR conditioning preparation. There was, an early attempt to examine Sokolov's assertions empirically for its implications about GSR conditioning. In this preparation, neutral, non-signal tone and light stimuli provide repetition and change conditions for subjects who are not instructed to pay special attention these stimuli, which are the only ones presented in what, to the subject, is a rather boring experiment. One set of findings was that as many as 12 repetitions of an alternating tone/light followed by a break in that repetition (Furedy, 1968), or as many as 15 repeated tone-light or lighttone pairings followed by a tone- or light-alone change trial (Furedy, 1969) failed to produce the Sokolov-predicted increase in GSR to change. One relatively non-controversial implication of these findings under these low-attentional conditions is that these experiments are essentially allocationof-attention studies, where it is the subject's decision whether to pay attention that determines whether s/he will register changes in stimulation that are clearly knowable if attention is drawn to them either by instructions or by some signal value. In addition, these findings seemed convincing to me and my collaborators that the OR confound for autonomic conditioning was not an empirically significant methodological issue (Furedy \& Poulos, 1977), but others (e.g., Badia, \& Defran, 1970; Siddle \& Remington, 1978; Stern \& Walrath 1977) were not convinced.

Still, while this cross-modal repetition-to-change preparation has not proved useful for resolving the OR versus CR controversy (which may, in the end, not be an empirically resoluble one), the preparation has turned out to be potentially useful for quite a different set of issues which we have been investigating recently in the laboratory of Dr. Pierre Flor-Henry, a psychiatrist at the Alberta Hospital, Edmonton, Canada.

The first modification in our thinking was a conceptual one having to do with the independent variables of repetition and change. The term "orienting response" suggests a non- cognitive, S-R function. However, given that the Sokolovian account of the effect of repetition and change refers to the "confirmation" and "disconfirmation," respectively, of a "neuronal model," it became clear to anyone who held the traditional distinction between cognitive and non-cognitive functions to be whether the expression was propositional (and hence had truth value) or non-propositional (and hence no truth value) that both the repetition and change manipulations involved cognitive rather than non-cognitive, response-like functions (see also Furedy, 1989). A psychophysiological confirmation of this cognitive vs. noncognitive distinction was provided in a study which employed the cross-modal repetition-to-change preparation used by Furedy (1968), but added finger temperature as another dependent psychophysiological variable. The results yielded a clear contrast between the previously measured GSR or, more precisely, conductance change response (SCR) and the newly measured finger temperature (Morrison, Furedy \& Flor-Henry, 2001). While the SCR, as in previous studies (e.g., Furedy, 1968; Ginsberg \& Furedy, 1974), decreased over repetition trials ("confirmation") and increased dramatically to the change trial ("disconfirmation"), finger temperature showed only an increase over all trials, whether these were repeated or changed trials. In other words, finger temperature was indexing the non-cognitive decrease in arousal as subjects adapted to the experiment, whereas the SCR reflected (cognitive) knowledge about repetition and change.

Another relevant distinction was that between perceptual and conceptual functions which I have referred to in connection with the watermaze studies discussed above. In the present psychophysiological context, when first reporting our results from the Alberta laboratory, we referred to this distinction as that between "stimulus-specific" and "statedrelated" novelty or change effects (Morrison, Furedy \& FlorHenry, 1996), but later reports recognized as reflecting the difference between perceptual and conceptual cognitive functions (Morrison et al., 2001).

The additional measured dependent psychophysiological variable that underlay this perceptual/conceptual distinction was that of the tonic electrodermal measure of skin conductance level (SCL) assessed 5 seconds before each trial. This contrasts with the SCR, which is the phasic increase in conductance occurring from 1 to 4 seconds following trial onset, a response that used to be referred to as the "GSR." One Sokolovian prediction that consistently proved difficult to confirm was that of "dishabituation." The dishabituation prediction in the repetition-to-change preparation is that responding to the repeated stimulus that is presented immediately after the change stimulus should also increase, though not perhaps to the degree of increase elicited by the change stimulus. As in other studies, the phasic SCR in the experiments run in the Alberta laboratory with the cross-modal repetition-to-change preparation failed to show any evidence of "dishabituation" (Morrison et al., 
1996). However, the newly measured SCL did show this increase after the post-change, re-presentation of the previously repeated stimulus, whereas, as, like the SCR, it decreased over repeated stimulus trials. We interpret SCL as indexing the conceptual cognitive knowledge of repetition and change in a series of stimuli. In terms of the more abstract concept of series of trials rather than individual trials, it makes sense for SCL to register the occurrence of change in the series, even after the previously (frequently) repeated stimulus is re-presented following the change stimulus - the series of stimuli has still changed at that point. In contrast, SCR reflects the (less abstract) perceptual knowledge of repetition and change in an individual stimulus. Hence the SCR does not increase to the re-presented, previously-repeated stimulus when it occurs following the change stimulus (Morrison et al., 2001).

The conceptual/perceptual distinction may seem rather esoteric, but it gained significant potential practical relevance when the Alberta medical research context allowed us an individual-differences-based clinical independent variable to that of $\operatorname{sex}^{3}$ (Furedy, Morrison \& Flor-Henry, 2001). In this clinical study we presented the cross-modal repetitionto-change preparation to 68 normal subjects, and unmedicated patients diagnosed as depressives $(\mathrm{N}=49)$ or as schizophrenics $(\mathrm{N}=47)$. The SCR results (which we interpret to indicate perception of each stimulus) indicated the expected decrease to repetition (i.e., habituation) and increase to change in all three groups, and some subtle intergroup differences with respect to rate of habituation (e.g., schizophrenics slower than other two groups) and size of increase to change (e.g., less for depressives than for normals). However, the SCL results (which we interpret to indicate conception of the stimulus series) yielded a unique and qualitative sexually-dimorphic pattern of outcomes. Specifically, the male schizophrenics failed to show any significant decrease in SCL to repetition or increase to change, whereas the SCL results of the other 5 sub-groups were appropriately sensitive to both repetition (i.e., decrease) and to change (i.e., increase).

This pattern of outcomes is consistent with at least two aspects of schizophrenia, namely that an essential characteristic (and one that distinguishes it from depression) is a loss of contact with some aspects of reality, and that it is more severe and has an earlier onset in males than females. It should also be noted that cruder experimental preparations such as presenting a few tones and measuring the responses elicited (whether these be autonomic or central such as the evoked response potential) will not serve to differentiate schizophrenics from normals or other clinical groups.
Just as Pavlov developed very specific experimental preparations to identify the individual differences in "strength of nervous system" as indexed by discrimination breakdown, so in other work designed to uncover the complexities of psychological functioning, there needs to be a differentiated view of experimental preparations employed, individual-differences variables defined, and relevant conceptual distinctions made. And as I have said before, I suggest that computer-metaphorical references to "information processing" in living organisms (i.e., non computers) will prove, in the long run, to be of little scientific or practical utility, no matter how currently popular this way of thinking may be.

Finally, to maximize both scientific and practical utilities, it is important to pay attention not only to the manipulation, but also to the observation of independent variables. This is the concept of melding the methods of experimental and differential psychology. And it was the physiologist, Pavlov, who pointed the way.

\section{References}

Algan, O., Furedy, J.J., Demirgoren S., Vincent, A., \& Pogun S. (1995). Effects of tobacco smoking on interhemispheric processing and psychophysiological responses during verbal and spatial tasks: Gender differences. Society for Neuroscience Abstracts, 21, 272.

Anderson, J. (1962). Studies in empirical philosophy. Sydney: Angus \& Robertson.

Badia, P., \& Defran, R.H. (1970). Orienting responses and GSR conditioning: A dilemma. Psychological Review, 77, 171-81.

Burnet, J. (1930). Early Greek philosophy. London: Adam \& Charles Black.

Cronbach, L.J. (1957). The two disciplines of scientific psychology. American Psychologist, 12, 671-684.

Eysenck, H.J. (1957). Sense and nonsense in psychology. Penguin: London.

Furedy, J.J. (1968). Human orienting reaction as a function of electrodermal versus plethysmographic response modes and single versus alternating stimulus series. Journal of Experimental Psychology, 77, 70-78.

Furedy, J.J. (1969). Electrodermal and plethysmographic OR components: Repetition of and change from UCS-CS trials with surrogate UCS. Canadian Journal of Psychology, 27, 127-135.

Furedy, J.J. (1988). On the relevance of philosophy for psychological research: A preliminary analysis of some influences of Andersonian realism. Australian Journal of Psychology, 40, 71-77.

\footnotetext{
3 Sex by itself did not affect either influence of either repetition or change on the psychophysiological dependent variables studied in the Alberta laboratory. More generally, while sex is often included as a factor in psychophysiological studies of the last two decades, it seldom produces significant differences.
} 
Furedy, J.J. (1989). The state of psychological theory as illustrated by Melzack's new conceptual nervous system model/theory: Strong on imaginativeness but weak in inference. Canadian Psychology, 30, 711-712.

Furedy, J.J. (1990, May). W(h)ither the discipline? An interactive symposium. Invited symposium of the Canadian Psychological Association Meetings, Ottawa, Canada.

Furedy, J.J. (1992). Reflections on human Pavlovian decelerative heart-rate conditioning with negative tilt as US: Alternative approaches. Integrative Physiological and Behavioral Science, $27,347-355$

Furedy, J.J. (1994). Review of J. Searle's the rediscovery of the mind. Biological Psychology, 37, 177-180.

Furedy, J. J. (2003). Pavlov Ivan (1849-1936). In J. Byrne (Ed.), Learning \& memory, The MacMillan psychology reference series ( $2^{\text {nd }}$ ed., pp. 516-520). New York: MacMillan.

Furedy, J. J., Heslegrave, R. J., \& Scher, H. (1984). Psychophysiological and physiological aspects of T-wave amplitude in the objective study of behavior. Pavlovian Journal of Biological Science, 19, 182-194.

Furedy, J.J., \& Klajner, F. (1978). Imaginational Pavlovian conditioning of large-magnitude cardiac decelerations with tilt as US. Psychophysiology, 15, 538-543.

Furedy, J.J., \& Poulos, C.X. (1976). Heart-rate decelerative Pavlovian conditioning with tilt as UCS: Towards behavioral control of cardiac dysfunction. Biological Psychology, 4, 93-106.

Furedy, J.J., \& Poulos, C.X. (1977). Short-interval classical SCR conditioning and the stimulus-sequence-change-elicited OR: The case of the empirical red herring. Psychophysiology, 14, 351-59.

Furedy, J.J., \& Poulos, C.X. (1978). A reply to Siddle and Remington on the OR/CR distinction in short-interval classical autonomic conditioning. Psychophysiology, 15, 610-611.

Furedy, J. J. \& Riley, D. M. (1984). Undifferentiated and "moatbeam" percepts in Watsonian-Skinnerian behaviorism. Behavioral and Brain Sciences, 7, 625-626.

Furedy, J.J., Church, R.M., Overmier, J.B., \& Spence, J.T. (1991). Unification issues in academic psychology: Internal and external centrifugal forces: A symposium. International Newsletter of Uninomic Psychology, 10, 3-8.

Furedy, J.J., Algan, O., Vincent, A., Demirgoren, S., \& Pogun, S. (1999). Sexually dimorphic effect of an acute smoking manipulation on skin resistance but not on heart-rate during a cognitive verbal task. Integrative Physiological and Behavioral Science, 34, 207-214.

Furedy, J.J., Morrison, J.W., \& Flor-Henry, P. (2001). Skin conductance levels reveal unique deficits in allocation of attention to repetition and change in male schizophrenics. Society for Neuroscience Abstracts, 27, part 1, Program 1, Program \#741.5, p. 585.

Gantt, W. H. (1991). Ideas are the golden coins of science. Integrative Physiological and Behavioral Science, 26, 68-73.

Ginsberg, S., \& Furedy, J.J. (1974). Stimulus repetition, change and assessments of sensitivities of the relationships among an electrodermal and two plethysmographic components of the orienting reaction. Psychophysiology, 11, 35-43.
Grigorian, N. A. (1974). Pavlov, Ivan Petrovich. In Dictionary of scientific biography (Vol. 10, pp. 431-5). New York: Scribner.

Jones, J. E. (1962). Contiguity and reinforcement in relation to CS-US intervals in classical aversive conditioning. Psychological Review, 69, 176-186.

Kanit, L., Taskiran, D., Furedy, J. J., Kulali, B., McDonald, R., \& Pogun, S. (1998). Nicotine interacts with sex in affecting rat choice between "look-out" and "navigational" cognitive style in the Morris Water Maze place learning task. Brain Research Bulletin, 46, 441-445

Kanit, L., Taskiran, D. Yilmaz, O., Balkan, B. Demirgoren, S., Furedy, J.J., \& Pogun, S., (2000a). Sexually dimorphic cognitive style in rats emerges after puberty. Brain Research Bulletin, 52, 243-248.

Kanit, L., Yilmaz, O., Taskiran, D., Kulali, B., Furedy, J.J., Demirgoren, S., \& Pogun, S. (2000b). Sexually dimorphic cognitive style, female sex hormones and cortical nitric oxide. Physiology and Behavior, 71, 277-87.

Kendler, H.H. (2002). Spence, Kenneth (1907-1967). In J. Byrne (Ed.), Learning \& memory, The MacMillan psychology reference series ( $2^{\text {nd }}$ ed., pp. 836-639). New York: MacMillan. Kimura, D. (1999). Sex and cognition. Cambridge, MA: MIT Press.

MacDougal, J.M., Dembroski, T.M., \& Krantz, D.S. (1981). Effect of types of challenge on pressure and heart rate responses in Type A and B women. Psychophysiology, 18, 1-9.

Maze, J. R. (1983). The meaning of behavior. London: Allen \& Unwin.

MacCorquodale, K., \& Meehl, P.E. (1951). Some methodological comments concerning expectancy theory. Psychological Review, $58,230-33$.

Moltz, H. (1957). Latent extinction and the fractional anticipatory goal response. Psychological Review, 64, 229-241.

Morrison, J.W., Furedy, J.J., \& Flor-Henry, P. (1996). Fate of four Sokolovian deductions in the electrodermal and vasomotor components of the orienting reaction: The picture remains confused. Psychophysiology, 33, S63.

Morrison, J.W., Furedy, J.J., \& Flor-Henry, P. (2001). Skin conductance responses, prestimulus levels, and prestimulus digital skin temperature levels in a cross-modal repetition-tochange orienting reaction paradigm. Psychophysiology, 38, S69.

Newhouse, P.A., Sunderland, T., Thompson, K., Tariot P.N., Weingartner, H., Mueller E.R., Cohen, R.M., \& Murphy, D.L. (1986). Intravenous nicotine in a patient with Alzheimer's disease. American Journal of Psychiatry, 143, 1494-1495.

Osgood, C.E. (1953). Method and theory in experimental psychology. New York: Oxford University Press.

Pogun, S. (2001). Sex differences in brain and behavior: Emphasis on nicotine, nitric oxide and place learning. International Journal of Psychophysiology, 42, 195-208.

Popper, K.R. (1960). The logic of scientific discovery. London: Hutchinson.

Prokasy, W.F., \& Ebel, H.C. (1967). Three components of the classically conditioned GSR in human subjects. Journal of Experimental Psychology, 73, 247-56. 
Rescorla, R. A. (1967). Pavlovian conditioning and its proper control procedures. Psychological Review, 74, 71-80.

Rescorla, R. A. (1988). Pavlovian conditioning: It's not what you think it is. American Psychologist, 43, 151-160.

Rescorla, R. A., \& Wagner, A. R. (1972). A theory of Pavlovian conditioning: Variations in the effectiveness of reinforcement and nonreinforcement. In A.H. Black \& W.F. Prokasy (Eds.), Classical conditioning: Current theory and research (pp. 6499). New York: Appleton-Century-Crofts.

Sahakian.B., Jones, G., Levy, R., Gray, J., \& Warburton, D. (1989). The effects of nicotine on attention, information processing, and short-term memory in patients with dementia of Alzheimer type. British Journal of Psychiatry, 154, 797-800.

Scher, H., Hartman, L., Furedy, J.J., \& Heslegrave, R.J. (1986). Electrocardiographic T-wave changes are more pronounced in Type A than Type B men during mental work. Psychosomatic Medicine, 48, 159-66.

Searle, J. (1992). The rediscovery of mind. Cambridge, MA: MIT Press. Sechenov, I. (1866). Refleksy golovnogo mozga. St. Petersburg: Tipographiia A. Golovachova.

Segal, E. M., \& Lachman, R. (1972). Complex behavior or higher mental process: Is there a paradigm shift? American Psychologist, 27, 45-55.

Siddle, D., \& Remington, R. (1978). Is the methodological OR problem for short interval classical conditioning an "empirical red herring"? Psychophysiology, 15, 609-10.
Sokolov, Y.N. (1960). Neuronal models and the orienting reflex. In M.A.B. Brazier (Ed.), The central nervous system and behavior (pp. 187-276). New York: Josiah Macey Foundation.

Sokolov, Y.N. (1963). Perception and the conditioned reflex. Oxford: Pergamon Press.

Spielberger, C.D. (1986). Psychological determinants of smoking behavior. In Tollison R.D. (Ed.), Smoking and society: Toward a more balanced assessment (pp. 89-134) Lexington, MA: Heath.

Spence, K. W. (1956). Behavior theory and conditioning. New Haven, CT: Yale University Press.

Spence, K.W., Haggard, D., \& Ross, L.E. (1958). UCS intensity and the associative (habit) strength of the eyelid CR. Journal of Experimental Psychology, 55, 404-11.

Staats, A. (1983). Psychology's crisis of disunity, philosophy and method for a unified science. New York: Praeger.

Stern, J.A., \& Walrath, L.C. (1977). Orienting responses and conditioning of electrodermal responses. Psychophysiology, 14, 334-342.

Stewart, M., Stern, J.A., Winokur, G., \& Fredman, S. (1961). An analysis of GSR conditioning. Psychological Review, 68, 60-67.

Watson, J. B. (1913). Psychology as the behaviorist views it. Psychological Review, 20, 158-177.

Received September 12, 2003

Revision Received September 23, 2003

Accepted October 6, 2003 